\title{
Study for the Pile Foundation on Steep Slope Applied in UHV Transmission projects
}

\author{
Jin Li and He Chuan \\ Hubei Electric Power Design Institute, Wuhan, China
}

\begin{abstract}
When designing a pile on the steep slope, the calculation is based on a hypothesis of horizontal ground. Obviously, it is difficult to estimate the difference between the calculation result and the actual loading behaviour of the pile foundation. For a UHV (Ultra High Voltage) power transmission project in China, results are compared by two kinds of methods. One is traditional theory; the other is numerical simulation method. It shows that quite different deformation of ground foundation occurs near two sides of the pile cap. The traditional calculating method for the pile foundation can consider the effect by increasing the part of the pile above the ground surface. Reasonability of the increased value can be assessed by the numerical method. The result of numerical simulation shows that the maximum deformation appears in the middle of the pile, but it occurs in the top of the pile by the traditional method. And deformation is evidently larger by the traditional method. Deformation curve is different between the traditional method and the numerical method which can consider frictional resistance around the pile. Quite different are vertical stress values of the pile obtained by two methods.
\end{abstract}

\section{Introduction}

With the implementation of Chinese "West-East electricity transmission project", "UHV (Ultra High Voltage) power transmission" and other significant energy strategies, the technology of $\pm 800 \mathrm{kV}$ HVDC power transmission has been widely used for the output of hydropower from the Jinsha River and Yalong River. Some projects have been put into operation, such as Xiangjiaba-Shanghai $\pm 800 \mathrm{kV}$ HVDC power transmission project, Jinping - Southern Jiangsu $\pm 800 \mathrm{KV}$ HVDC power transmission project. With the construction of these important projects, power transmission towers are higher, so the vertical and the lateral load applied on one foundation are getting larger and larger [1].

As is known to all, China has rich hydropower resources in Sichuan, Yunnan, Tibet, and so on. There are more high mountains, steep slopes in these regions. So the pile foundation on steep slope is very common [2-3]. Currently, it is based on the hypothesis of flat ground layer when designing a pile foundation subjected to horizontal load, which is suggested by the code. So it is difficult for engineers either designing the pile foundation on steep slope or locating the tower near a steep slope. Thus, it is valuable in theory and practice to study loading behaviour of piles on steep slope and its calculation method.

Foreign researchers have made some study earlier about the pile foundation bearing horizontal load. Achievements have been obtained in the field of pile groups, deep foundations, pile on slope or Rigid soil, etc [4-7]. Recently, with the construction of highways, hydro projects, and UHV power transmission projects in China, it have made some researches about design methods for pile foundation on slope and the interaction between pile and soil. These have produced many findings [8-11].

However, few of results have referred to the loading behaviour of pile foundation pulled up on a steep slope [8]. For power transmission projects, uplift loads often play a decisive role in the design of pile foundation, which is typically different from piles in other projects.

Based on the available achievements, theoretical analysis and numerical calculation are both conducted for a pile foundation on steep slope in a Chinese UHV power transmission project. It shows distinctly the loading behaviour of pile foundation on steep slope either pulling up or pressing down, which can offer data support for designing the pile foundation on steep slope in transmission projects.

\section{Project background}

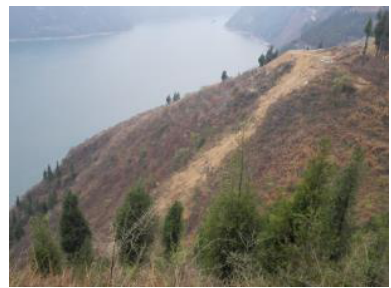

Figure 1. Location of the power transmission towe

$\mathrm{A} \pm 800 \mathrm{kV}$ HVDC power transmission project passes through five provinces in China, the flight distance of 
which is over $2000 \mathrm{~km}$. The elevation difference of this project is nearly $2900 \mathrm{~m}$. Almost $60 \%$ of the line is in steep mountains, involving a large number of pile foundations on steep slope.

In this project a tower has a rotation of turning left $0^{\circ} 37^{\prime}$. The location is in the ridge slope of a mountain along the Yangtze River, and it is a cypress grove (shown in Fig. 1). The front slope occurrence is $220^{\circ} \angle 15^{\circ} \sim 20^{\circ}$, and the left slope occurrence is $140^{\circ} \angle 37^{\circ} \sim 43^{\circ}$, and the right slope occurrence is $310^{\circ} \angle 35^{\circ} \sim 42^{\circ}$. Dolomitic limestone appears sparsely in this area, the occurrence of which is $347^{\circ} \angle 18^{\circ}$.

Bedrock under the tower is dolomitic limestone, covered with a thin layer. The cover is of Quaternary eluvial hard plastic cohesive soil which has a thickness of $0.3 \sim 2.5 \mathrm{~m}$. Quaternary cover layer's thickness is generally $0.0 \sim 1.8 \mathrm{~m}$ around the tower. In the water-eroded groove, some is relatively thicker, and the thickness is up to $3.8 \mathrm{~m}$. The mechanical parameters of each layer are shown in Table 1 .

Table 1. Mechanical parameters of the rock and soil

\begin{tabular}{|c|c|c|c|c|c|c|c|}
\hline $\begin{array}{c}\text { Stratigraphic } \\
\text { position }\end{array}$ & Name & $\begin{array}{c}\text { Weight } \\
\left(\mathbf{k N} / \mathbf{m}^{\mathbf{3}}\right)\end{array}$ & $\begin{array}{c}\text { Elastic modulus } \\
(\mathbf{M P a})\end{array}$ & $\begin{array}{c}\text { Poisson } \\
\text { ratio }\end{array}$ & $\begin{array}{c}\text { Cohesion } \\
(\mathbf{k P a})\end{array}$ & $\begin{array}{c}\text { Internal friction } \\
\text { Angle }\left(\mathbf{(}^{\circ}\right)\end{array}$ & $\begin{array}{c}\text { Tensile strength } \\
(\mathbf{k P a})\end{array}$ \\
\hline top & $\begin{array}{c}\text { silty clay containing rock } \\
\text { fragments }\end{array}$ & 19.0 & 5.5 & 0.42 & 40 & 10 & 10 \\
\hline middle & $\begin{array}{c}\text { Weathered dolomitic } \\
\text { limestone }\end{array}$ & 22.5 & 26 & 0.30 & 60 & 22 & 60 \\
\hline bottom & $\begin{array}{c}\text { Weak weathered dolomitic } \\
\text { limestone }\end{array}$ & 22.5 & $2.8 \mathrm{E} 4$ & 0.26 & 130 & 30 & 200 \\
\hline
\end{tabular}

Table 2. Design parameters of the pile

Table 3. Mechanical parameters of the pile

\begin{tabular}{|c|c|c|}
\hline diameter $\mathbf{( m )}$ & Depth under ground $(\mathbf{m})$ & Depth above ground $(\mathbf{m})$ \\
\hline 2.6 & 9.0 & 6.0 \\
\hline
\end{tabular}

\begin{tabular}{|c|c|c|}
\hline Weight $\left(\mathbf{k N} / \mathbf{m}^{\mathbf{3}}\right)$ & Elastic Modulus (GPa) & Poisson ratio \\
\hline 24.0 & 28.0 & 0.30 \\
\hline
\end{tabular}

Table 4. Load cases

\begin{tabular}{|c|c|c|c|c|}
\hline \multicolumn{2}{|c|}{ Case number } & Load in direction X (kN) & Load in direction Y (kN) & Load in direction Z (kN) \\
\hline \multirow{2}{*}{ Pressing down } & standard value 1 & 591.11 & -2868.15 & 523.70 \\
\cline { 2 - 5 } & Design value1 & 798 & -3872 & 707 \\
\hline \multirow{2}{*}{ Pulling up } & standard value2 & 477.78 & 1951.85 & 377.04 \\
\cline { 2 - 5 } & Design value2 & 645 & 2635 & 509 \\
\hline
\end{tabular}

\section{Theoretical analysis}

Theoretical calculation adopts the method recommended in "Technical code for building pile foundations" [12], [13] (hereinafter referred to as "the Code"). Design parameters of the pile are listed in Table 2 and Table 3. Load cases are shown in Table 4. Cases listed in table 4 are calculated according to the Code. Calculation diagram is shown in Fig. 2.

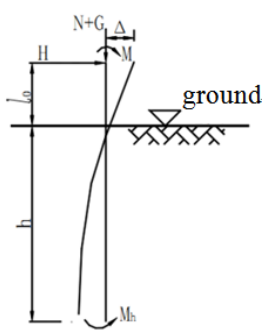

Figure 2. Calculation diagram of the pile

Assuming the cross-section of the pile is a plane anytime, at the ground surface, the horizontal displacement $x_{0}$ and rotation angle $\varphi_{0}$ should be

$$
\left\{\begin{array}{l}
x_{0}=H_{0} \delta_{H H}+M_{0} \delta_{H M} \\
\varphi_{0}=-\left(H_{0} \delta_{M H}+M_{0} \delta_{M M}\right)
\end{array}\right.
$$

Considering as a single pile, then $M_{0}=M+H l_{0}, H_{0}=H$, coefficients of $\delta_{\mathrm{HH}}, \delta_{\mathrm{MH}}, \delta_{\mathrm{HM}}$ and $\delta_{\mathrm{MM}}$ are determined from the table in the code.

Horizontal displacement of the pile top is

$$
\Delta=x_{0}-\varphi_{0} l_{0}+\Delta_{0}
$$

In which $\Delta_{0}=\frac{H l_{0}{ }^{3}}{3 n E I}+\frac{M l_{0}{ }^{2}}{2 n E I}$, EI is bending stiffness of the pile.

Results calculated for each load case are shown in Tables 5 and Table 6 . The calculation increases the depth above ground to consider the effect of the actual steep slope. It can be found that the top of the pile has a displacement either in the case of pulling up or in the case of pressing down. Compared calculation results of two load cases, the ratio of the value of the pile top displacement is proportional to that of the absolute value of the resultant force of horizontal $\operatorname{loads}(\mathrm{X}$ and $\mathrm{Z}$ direction). Besides, the position of the maximum bending moment is at the same depth in two cases, and the maximum stress occurs at the bottom of the pile. Due to the assumption of flat ground layer, it is difficult to consider the missing soil in the outside of the steep slope. Usually it is a simple and approximate method to increase the part of the pile above the ground surface. Obviously the results by this method need to be checked and compared by other methods. 
Table 5. Calculation results of deformation and internal force

\begin{tabular}{|c|c|c|c|c|c|}
\hline & & Design value1 & Design value2 & Standard value1 & Standard value 2 \\
\hline \multirow{5}{*}{$\begin{array}{l}\text { At the } \\
\text { ground } \\
\text { surface }\end{array}$} & Horizontal displacement $(\mathrm{mm})$ & 4.01 & 3.09 & 2.97 & 2.29 \\
\hline & Rotation angle(FI) (rad) & -0.001039 & -0.000801 & -0.000770 & -0.000593 \\
\hline & Axial force $(\mathrm{kN})$ & -4636.538 & 1870.462 & -3632.688 & 1187.312 \\
\hline & Shear $(\mathrm{kN})$ & 1066.139 & 821.648 & 789.730 & 608.632 \\
\hline & Moment $(\mathrm{kN} \cdot \mathrm{m})$ & 6396.836 & 4929.890 & 4738.377 & 3651.792 \\
\hline & top displacement (mm) & 10.25 & 7.90 & 7.59 & 5.85 \\
\hline
\end{tabular}

Table 6. Calculation of bending moment, maximum stress (depth is 0 at the design ground surface)

\begin{tabular}{|c|c|c|c|c|c|}
\hline \multicolumn{2}{|c|}{} & Design value1 & Design value2 & Standard value1 & Standard value2 \\
\hline \multirow{3}{*}{ Moment } & Maximum bending moment $(\mathrm{kN} \cdot \mathrm{m})$ & 7893.379 & 6083.241 & 5846.923 & 4506.131 \\
\cline { 2 - 6 } & Axial force at the maximum bending moment $(\mathrm{kN})$ & -4922.84 & 1584.16 & -3918.99 & 901.01 \\
\cline { 2 - 6 } & Corresponding depth $(\mathrm{m})$ & 2.247 & 2.247 & 2.247 & 2.247 \\
\hline \multirow{2}{*}{ Stress } & Maximum stress $(\mathrm{KPa})$ & -400.133 & -308.373 & -296.394 & -228.426 \\
\cline { 2 - 6 } & Corresponding depth (m) & 9 & 9 & 9 & 9 \\
\hline
\end{tabular}

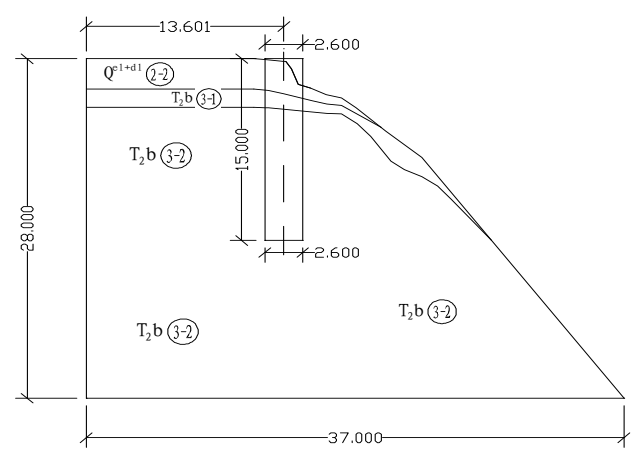

(a) design section (unit: $\mathrm{m}$ )

Figure 3. The model of pile foundation on the steep slope

\section{Setting of numerical analysis}

\subsection{Model and parameters}

Numerical calculation is carried out by the method of FFM. The design section and calculation model are shown in Figure 3. The whole calculation model is divided into 26660 elements, 28689 nodes. According to the geological survey data, the parameters of the rock and soil are identified in Table 1 based on practical conditions. And the physical and mechanical parameters of the pile can be found in table 3 .

\subsection{Simulation method of pile-soil interaction}

In order to fully evaluate the pile-soil interaction, it is necessary to determine stress and strain distribution of the pile and the soil respectively, and the data of displacement and stress distribution on the contact area. Then a comprehensive study can be made about factors influencing the pile-soil interaction. This problem is one of contact problems between different kinds of media in solid mechanics. It is a typical nonlinear problem, which could contain nonlinear material, or nonlinear contact, etc. In the calculation, the interaction between the pile and the soil is simulated by setting contact surfaces between the

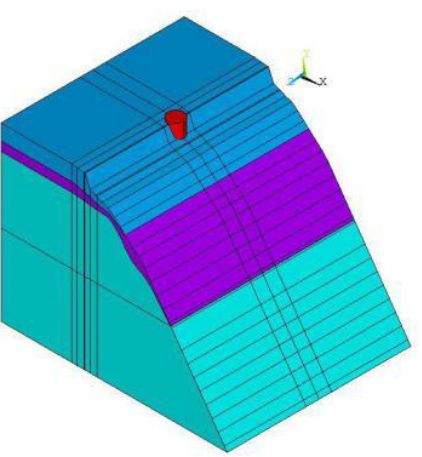

(b) material zoning

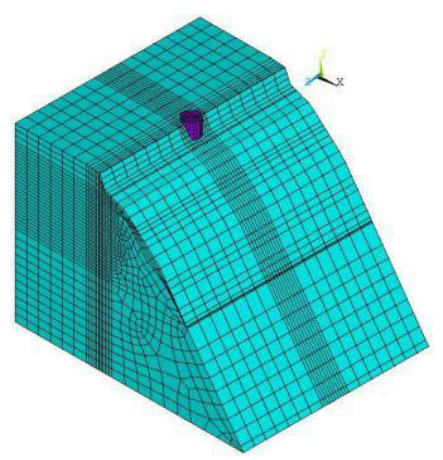

(b) meshing pile and the soil. That is to say, Surface-to-Surface contact is built. Then the interaction effect between the two kinds of media is represented by the contact stiffness, $\mathrm{F}=\mathrm{k} \Delta$ ( $\mathrm{k}$ is the contact stiffness). This is shown in Fig. 4.

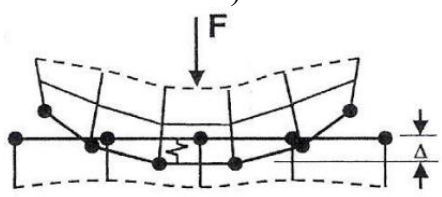

Figure 4. Schematic diagram of pile-soil contact

Eight-node isoparametric element is used in rock and soil (SOLID185). When analyzing the contact of the pile and soil, surfaces of the pile are of rigid target surface (TARGE170), and surfaces of the rock and soil are of contact surface (CONTA174). The target surface and the contact surface are combined together to form a contact pair.

\section{Results and discussion}

\subsection{Deformation behavior of the pile}

In view of the horizontal displacement of the pile, at the depth of $6 \mathrm{~m}$ from the pile top, in two cases the result of the pile axis by numerical simulation is close to that of standard values of loads by theoretical calculation according to the code (see Table 7). 
Table 7. deformation at the section of $6 \mathrm{~m}$ depth of the pile

\begin{tabular}{|c|c|c|}
\hline \multirow{2}{*}{ Method } & \multicolumn{2}{|c|}{ Horizontal displacement (mm) } \\
\cline { 2 - 3 } & in pressing case & in pulling case \\
\hline Theoretical method in the code & 2.97 & 2.29 \\
\hline Numerical method & 2.46 & 2.41 \\
\hline
\end{tabular}

Based on the traditional theory suggested by the code, the result is reliable using a larger height value $(6.0 \mathrm{~m})$ of the pile above ground surface than the actual height. The horizontal distance is $7.0 \mathrm{~m}$ from the centre of the section at the depth of $6.0 \mathrm{~m}$ to the slope surface. It is about 2.7 times the diameter of the pile. Overall, numerical results show that the maximum deformation occurs in the middle of the pile and theoretical results is at the top of the pile (see Table 5 and Fig. 5). Considering a free height of $6.0 \mathrm{~m}$, the theoretical deformation is significantly larger. In fact the height of $6.0 \mathrm{~m}$ is surrounded by soil and rock on the steep slope.

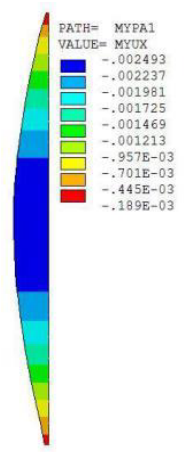

(a) in pressing case

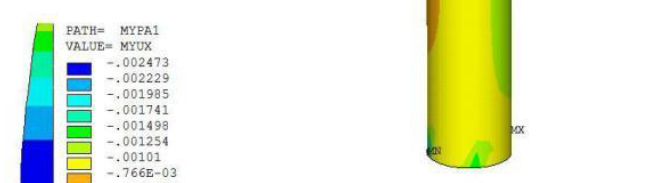

(a) in pressing case

of the pile and theoretical results is at the top of the pile (see Table 5 and Fig. 5). Considering a free height of $6.0 \mathrm{~m}$, the theoretical deformation is significantly larger. In fact the height of $6.0 \mathrm{~m}$ is surrounded by soil and rock on the steep slope.

In view of vertical displacement, the tension side obviously has a difference with the compression side of the pile (see Fig. 6), which is consistent with the characteristics of bending deformation. This could not be considered by the theoretical method.

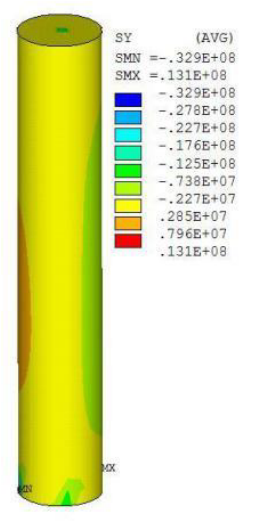

Figure 7. Vertical stress (SY) of the pile (unit: $\mathrm{Pa}$ )

\subsection{Vertical stress (Sy) of the pile}

In view of vertical stress (see Fig. 7), in two cases the traditional method or the numerical method both show that maximum vertical stress emerged at the bottom of the pile. Two methods also reveal that the position of maximum moment is basically same, which is located on the middle of the pile.

From the view of stress value, it is quite different between theoretical calculation and numerical simulation. The theoretical calculation assumes that there is no lateral frictional force, and adopts the equation of deflection curve. However, the numerical simulation results, which have considered the frictional resistance, show that there are some differences in the curves of deformation, which leads to the difference of the value of stress in $\mathrm{Y}$ direction. In addition, numerical results indicate stress concentration at the bottom of the pile.

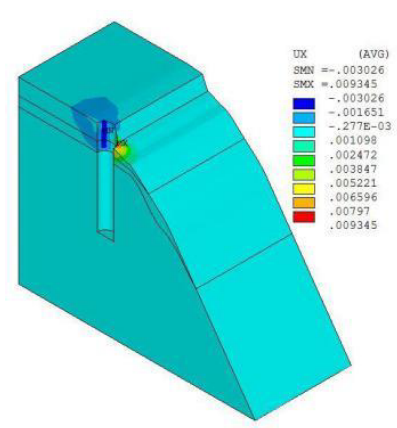

(a) horizontal displacement (unit: $\mathrm{m}$ )

Figure 8. Loading behaviour of the foundation in pressing case (unit: $\mathrm{Pa}$ )

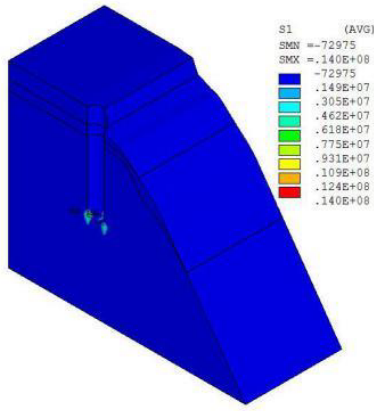

(b) the first principal stress the pile above ground surface than the actual height. The horizontal distance is $7.0 \mathrm{~m}$ from the centre of the section at the depth of $6.0 \mathrm{~m}$ to the slope surface. It is about 2.7 times the diameter of the pile. Overall, numerical results show that the maximum deformation occurs in the middle

\subsection{Foundation deformation and stress}


Fig. 8 shows the horizontal displacement and the first principal stress distribution in pressing case. Fig. 9 shows them in pulling case. Due to the landform of steep slope, displacement down slope is large. In two cases it could see obvious deformation of the covering soil layer near the pile cap, but it is not obvious for the horizontal displacement of the bedrock. Compared to results of the pile foundation in flat ground, the pile foundation on steep slope presents an asymmetry image as to the ground deformation near the pile head. This is because of the difference of in-situ stress between flat ground and steep slope.

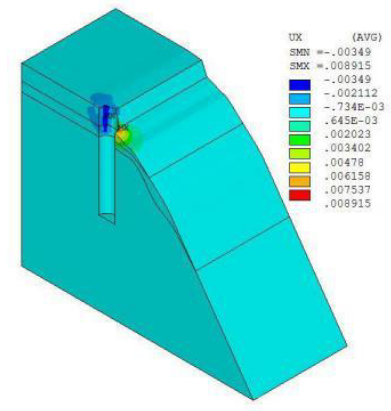

(a) horizontal displacement (unit: $\mathrm{m}$ )

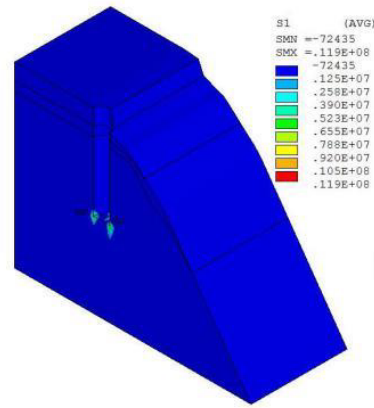

(b) the first principal stress (unit: $\mathrm{Pa}$ )
Figure 9. Loading behaviour of the foundation in pulling case

Stress concentration also can be seen for the first principal stress at the bottom of the pile in two load cases. This is because of the rotation of the pile occurs in the foundation under horizontal loads, when considering pilesoil interaction by contact surfaces.

\section{Conclusions}

Based on the above analysis, conclusions can be made as follows:

(1) For the pile on steep slope, the traditional calculation models could basically meet the need of UHV transmission projects, but the effect of steep slope can never be ignored. It is a simple and effective method to increase the part of the pile above the ground surface. The value increased is suggested by a formulation of (2.5 3.0) $\times \mathrm{D} \times \tan \alpha$, in which $\mathrm{D}$ is the diameter of the pile , and $\alpha$ is the dip angle of the steep slope.

(2) The result of numerical simulation shows that the maximum deformation appears in the middle of the pile which has been supposed to appear on the head of the pile according to theoretical calculation. It is considered unconstrained for the part above the ground surface increased factitiously, but this part is surrounded by soil and rock on the steep slope. The theoretical deformation is obviously larger than the actual value. When subjected to horizontal load, the theoretical calculation assumes that there is no lateral frictional force around the pile, and adopts the equation of deflection curve. However, the numerical simulation results, which have considered the frictional resistance, show that there are some differences in the deformation curves. Two methods have showed the same position of the maximum moment, which is located in the middle of the pile.
(3) For the pile foundation on steep slope, numerical simulation presents an asymmetry image as to the ground deformation near the pile head. This is because of the difference of in-situ stress between flat ground and steep slope. Due to the effect of horizontal loads, stress concentration is obvious at the bottom of the pile foundation on steep slope either in pressing case or in pulling case.

Overall, the topography of steep slope will result to obvious differences of the deformation and stress distribution on both sides of the pile foundation. When considering surface frictional resistance of the pile, the deformation of the pile is more complicated. So the method of numerical simulation can be used for checking results by the theoretical method according to the code when designing pile foundation on steep slope for UHV transmission projects. And further studies should be made to modify the traditional theory considering the effect of a steep slope.

\section{References}

1. Shu Yinbiao, Liu globe, Gaoli Ying, et al. $800 \mathrm{kV}$ 6400MW UHVDC transmission project design. Power system technology, 30 (1):1-8, (2006).

2. Zhang Yongjie, Li Youjun, Zhao Minghua, et al. Design and calculation method of pile groups under high and steep slope. Chinese Journal of highway and transport, 27 (10):84-92, (2014).

3. Zhao Ming-hua, Yin Ping-bao, Zhang Yong-jie, et al. The Design and Calculation Method of Pile-column Bridge Pile Foundation in High and Steep Slope. Engineering Mechanics, 30 (3):106-111, (2013).

4. Alizadeh, M., and Davisson, M. T. Lateral load test on piles-Arkansas River Project. J. Soil Mech. and Found. Div., ASCE, (96), 1583-1603, (1970).

5. ANG L M, MCVAY M C, HAN S J, et a1. Effects of dead loads on the lateral response of battered pile groups. Canadian Geotechnical Journal, (39): 561575, (2002).

6. Reese LC, Welch RC. Lateral loading of deep foundations in stiff clay. Journal of Geotechnical Engineering Division, ASCE, 101(GT7):633-649, (1975).

7. Gabr MA, Borden RH. Lateral analysis of piers constructed on slopes. Journal of Geotechnical Engineering. 116(12):1831-1850, (1990).

8. He Jian. Testing study on anti-draw bearing properties of cast-in-place rock-socked pile . Chinese Journal of Rock Mechanics and Engineering, 23 (2): 315-319, (2004).

9. Rao Pingping, Li Jingpei, Zhan Yue. The adjacent slopes sink pile squeezing effect of soil particle flow numerical simulation. Journal of Water Resources \& Water Engineering, 24 (4):1-5, (2013).

10. Gong Xiarrbing, Yang Minghui, Zhao Minhua, et al. Load-bearing Mechanism Model Test for Bridge Pile Foundation in High-steep Transverse Slope. China Journal of Highway and Transport, 26(2):56-62, (2013). 
11. Cheng Liu-yong, Xu Xi-chang, Chen Shan-xiong, et al. Model test and numerical simulation of horizontal bearing capacity and impact factors for foundation piles in slope . Rock and Soil Mechanics, 35(9): 2685-2691, (2014).

12. Electric Power Planning \& Engineering Institute. DL/T 5219-2014 Technical code for design of foundation of overhead transmission line. Beijing: China Planning Press, (2014).

13. The Professional Standards Compilation Group of People's Republic of China. JGJ94-2008 Technical Code for Building Pile Foundations. Beijing: China Architecture \& Building Press, (2008). 